\title{
22. PALEOMAGNETIC EVIDENCE FOR MOTION OF THE PACIFIC PLATE FROM LEG 32 BASALTS AND MAGNETIC ANOMALIES ${ }^{1}$
}

\author{
Roger L. Larson and William Lowrie, Lamont-Doherty Geological Observatory, Palisades, New York
}

\begin{abstract}
Magnetic properties were measured on basalt samples from four DSDP Leg 32 sites in the northwestern Pacific. All of the sites have reasonably stable magnetization directions during demagnetization that probably correspond to the original remanent directions of the samples. The samples from three of the four sites are assumed to have the following magnetic polarities determined from magnetic anomaly profiles made near these sites: Hole 303A, normal; Site 304, reversed; Site 307, normal. The cross-sectional shapes of the anomaly profiles and the remanent magnetic inclinations of the basalt samples yield concordant paleolatitude information at all three sites that supports a net northward motion of the Pacific plate since the Mesozoic.
\end{abstract}

\section{INTRODUCTION}

Paleomagnetic studies were carried out on partially oriented basalt samples with the intentions of (1) describing their basic magnetic properties and (2) comparing the magnetization inclinations with those expected from magnetic anomaly modeling studies. The basalts are from Hole 303A and Site 304 on Mesozoic anomalies M4 and M9 of the Japanese lineation sequence, from Site 307 on Mesozoic anomaly M21 of the Hawaiian lineations, and from Site 313, which was drilled in the Mid-Pacific Mountain seamount province. The first three are typical oceanic basement basalts, the last appears to be an alkali basalt.

All of the basalts are fine grained and all show alteration due to ocean-floor weathering. Hole $303 \mathrm{~A}$ is only slightly altered, and the five samples were taken from at least three cooling units that were probably originally extrusive flows. At Site 304 the alteration is more extensive, and the 11 samples possibly all come from a single cooling unit. Site 307 samples are all highly weathered, but the amount of weathering decreases generally with depth; at least six cooling units are represented. The Site 313 samples represent possibly three cooling units. The Early Cretaceous to Late Jurassic ages of the overlying sediments agree generally with the ages predicted for the associated magnetic anomalies (Larson and Pitman, 1972 ) at the Mesozoic lineation sites. At Site 313 the Late Cretaceous sediment age suggests that these basalts are considerably younger than those from the magnetic lineation sites.

'Lamont-Doherty Geological Observatory Contribution No. 2147.

\section{MAGNETIC PROPERTIES}

\section{Natural Remanent Magnetization}

Natural remanent magnetizations (NRM) of all samples were measured with a spinner magnetometer; susceptibilities $(k)$ were measured with an AC bridge (Figure 1). The site mean values of NRM intensity (Table 1) are somewhat higher than the average of $2 \times 10^{-3} \mathrm{G}$ found in other DSDP basalts (Lowrie, in press), except at Site 307 which gives a lower-than-average site mean. The site mean susceptibilities are also higher than average $\left(0.6 \times 10^{-3} \mathrm{G} / \mathrm{oe}\right)$, again with the exception of Site 307.

The modified Königsberger ratio, $Q n^{\prime}(=\mathrm{NRM} / k$ ) ranges from 0.2 to 20 , but most values are only slightly greater than 1 (Figure 1). At Site 307, where both NRM and $k$ show the widest range of values, the $Q n^{\prime}$ ratio also shows a wide variation; the NRM appears to increase as the square of the susceptibility. Because sample-by-sample petrologic data were not obtained, describing the degree of weathering of individual samples, we could not establish whether this is fortuitous or is an effect of the decrease in weathering with depth at Site 307.

The values of the 1965.0 International Geomagnetic Reference Field at each site were used to calculate the Königsberger ratios, which average substantially greater than one at each site (Table 1).

\section{Magnetic Mineralogy}

Curie point analysis was carried out to determine the magnetic mineralogy of several samples from each site. Small chips of basalt were ground to a coarse powder and heated in air in a vertical motion type, automatically recording Curie balance. All of the thermomagnetic curves are irreversible, and typical of those observed for deuteric oxidation class I basalts. The Curie points observed during heating range from $270^{\circ} \mathrm{C}$ to $410^{\circ} \mathrm{C}$, and during cooling they range from $530^{\circ} \mathrm{C}$ to $550^{\circ} \mathrm{C}$, corresponding to a low-titanium magnetite. 


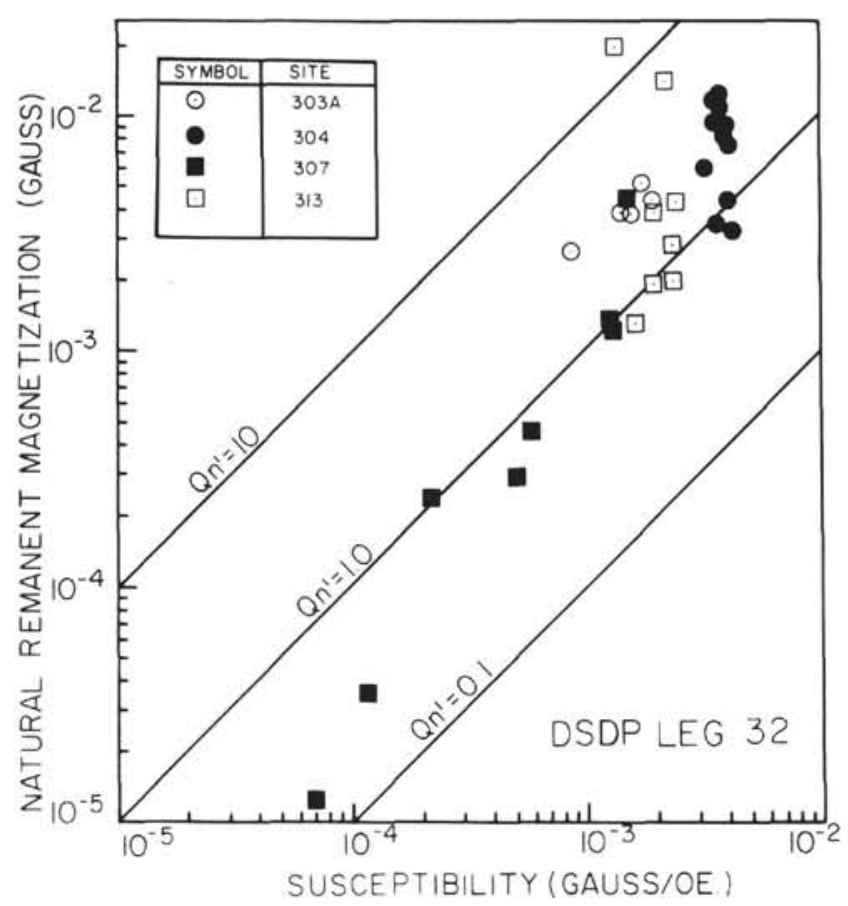

Figure 1. Intensities of natural remanent magnetization (NRM) and susceptibility (k) of Leg 32 basalts. $Q_{n}$ ' is the ratio $N R M / \mathrm{k}$.

TABLE 1

Site Mean Values of Natural Remanent Magnetization (NRM), Susceptibility $(k)$, Königsberger Ratio, and Curie Temperature

\begin{tabular}{lccccc}
\hline Site & $\begin{array}{c}\text { Number } \\
\text { of Samples }\end{array}$ & $\begin{array}{c}\text { NRM } \\
\left(10^{-3} \mathrm{G}\right)\end{array}$ & $\begin{array}{c}k \\
\left(10^{-3} \mathrm{G} / \mathrm{oe}\right)\end{array}$ & $\begin{array}{c}\text { Königs- } \\
\text { berger } \\
\text { Ratio }\end{array}$ & $\begin{array}{c}\text { Curie } \\
\text { Point } \\
\left({ }^{\circ} \mathrm{C}\right)\end{array}$ \\
\hline $303 \mathrm{~A}$ & 5 & 3.95 & 1.48 & 5.95 & 335 \\
304 & 11 & 7.96 & 3.74 & 4.91 & 275 \\
307 & 8 & 1.01 & 0.68 & 2.68 & 410 \\
313 & 8 & 6.28 & 1.98 & 10.5 & 410 \\
\hline
\end{tabular}

When the magnetic mineral in an oceanic basalt is titanomagnetite, initial Curie points of $150^{\circ} \mathrm{C}$ to $250^{\circ} \mathrm{C}$ are usually found; the actual value depends on the titanium content. One of the effects of maghemitization is elevation of the Curie temperature (Ade-Hall et al., 1971). Oceanic basalt Curie points in the range observed in the Leg 32 samples (Table 1) are normally associated with the cation-deficient form, titanomaghemite (Lowrie, in press). The oxidation process also causes a reduction in NRM intensity, but probably does not alter significantly the NRM direction (Marshall and Cox, 1972). It is probable, therefore, in spite of the altered condition of these basalts, that the original remanent directions are preserved.

\section{Remanent Magnetization Stability}

Alternating field (AF) demagnetization in progressively higher fields was used to investigate the stability of the remanent magnetization of each specimen. Vector diagrams illustrating the stability of representative specimens from each hole are shown in Figure 2. A stability index similar to that of Briden (1972) was
303 A $9-|-5|$
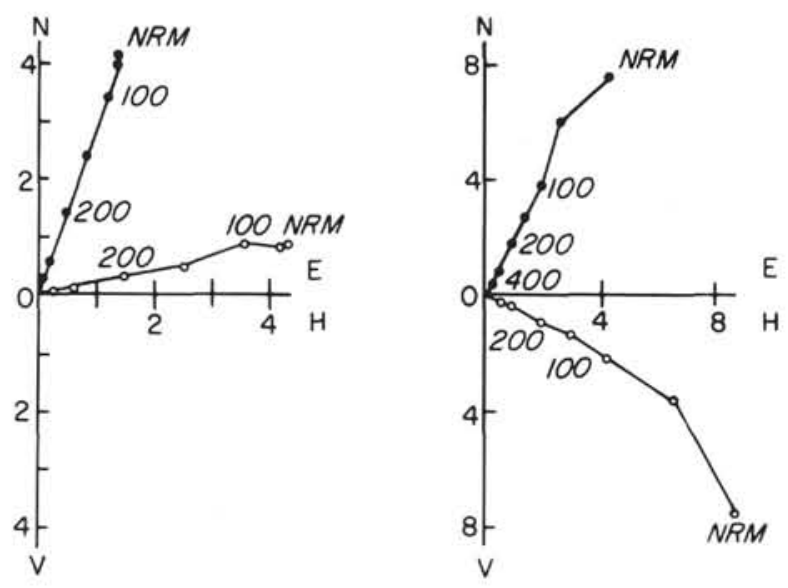

$$
307-13-3-144
$$

$313-43-2-93$
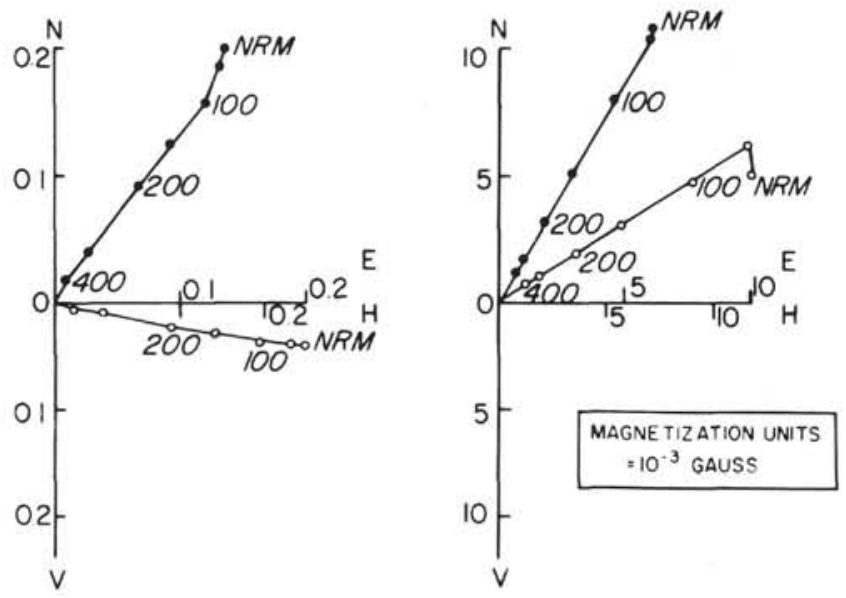

Figure 2. Vector diagram showing the AF demagnetization stability of Leg 32 basalt remanent magnetizations. The northward $(N)$ and eastward $(E)$ components define the declination variation (solid circles) relative to an arbitrary zero; the horizontal $(H)$ and vertical (V) components define the inclination variation (open circles). Numbers on each line refer to the peak demagnetizing field intensity in oersteds.

used to determine the most stable direction of magnetization for each sample. These directions, the fields at which they were obtained, and the direction of NRM for comparison are shown in Table 2. The median destructive field (MDF) was determined for each sample, and the fraction of the NRM remaining after AF treatment in 100 oe.

Stable magnetic properties were found at Hole 303A and Site 307. At Sites 304 and 313 the magnetizations are a little less stable in intensity; MDF is sometimes less than 100 oe, and sometimes less than $50 \%$ of the NRM remains after 100 oe AF (Table 2). The directional magnetic properties are generally very stable (Figure 2 ), and there was no difficulty in determining the stable direction for each sample. 
TABLE 2

Stability of Each Sample Against AF Demagnetization

\begin{tabular}{|c|c|c|c|c|c|c|c|}
\hline \multirow{2}{*}{$\begin{array}{l}\text { Sample } \\
\text { (Interval } \\
\text { in } \mathrm{cm} \text { ) }\end{array}$} & \multicolumn{2}{|c|}{ NRM } & \multicolumn{2}{|c|}{$\begin{array}{c}\text { After AF } \\
\text { Demagnetization }\end{array}$} & \multirow{2}{*}{$\begin{array}{l}H_{d} \\
\text { (oe) }\end{array}$} & \multirow{2}{*}{$\begin{array}{l}\text { MDF } \\
\text { (oe) }\end{array}$} & \multirow{2}{*}{$\begin{array}{c}J_{100} / \mathrm{NRM} \\
(\%)\end{array}$} \\
\hline & D & I & D & I & & & \\
\hline \multicolumn{8}{|l|}{ Hole 303A } \\
\hline $\begin{array}{c}9-1,51 \\
9-1,98 \\
9-1,120 \\
10-1,56 \\
10-1,91\end{array}$ & $\begin{array}{r}270 \\
314 \\
208 \\
69 \\
64\end{array}$ & $\begin{array}{r}-11 \\
-18 \\
-11 \\
16 \\
10\end{array}$ & $\begin{array}{r}269 \\
311 \\
210 \\
70 \\
64\end{array}$ & $\begin{array}{r}-12 \\
-12 \\
-11 \\
13^{a} \\
9^{a}\end{array}$ & $\begin{array}{r}200 \\
150 \\
200 \\
150 \\
50\end{array}$ & $\begin{array}{l}166 \\
225 \\
173 \\
179 \\
205\end{array}$ & $\begin{array}{l}83 \\
97 \\
89 \\
90 \\
94\end{array}$ \\
\hline \multicolumn{8}{|l|}{ Site 304} \\
\hline $\begin{array}{l}15-1,90 \\
15-1,124 \\
15-2,8 \\
15-2,60 \\
16-1,82 \\
16-1,112 \\
16-2,90 \\
16-2,132 \\
16-3,110 \\
16-4,19 \\
16-4,47\end{array}$ & $\begin{array}{r}120 \\
143 \\
56 \\
94 \\
264 \\
101 \\
277 \\
213 \\
211 \\
58 \\
200\end{array}$ & $\begin{array}{l}-8 \\
34 \\
31 \\
41 \\
16 \\
29 \\
41 \\
39 \\
24 \\
32 \\
13\end{array}$ & $\begin{array}{r}149 \\
141 \\
60 \\
96 \\
264 \\
127 \\
283 \\
205 \\
225 \\
55 \\
212\end{array}$ & $\begin{array}{r}19 \\
29 \\
24 \\
24 \\
18 \\
26 \\
29 \\
23 \\
11 \\
28 \\
6\end{array}$ & $\begin{array}{r}100 \\
50 \\
50 \\
150 \\
50 \\
150 \\
200 \\
200 \\
100 \\
100 \\
200\end{array}$ & $\begin{array}{r}69 \\
61 \\
80 \\
82 \\
117 \\
86 \\
59 \\
104 \\
132 \\
87 \\
70\end{array}$ & $\begin{array}{l}28 \\
28 \\
41 \\
42 \\
57 \\
43 \\
30 \\
52 \\
68 \\
40 \\
27\end{array}$ \\
\hline \multicolumn{8}{|l|}{ Site 307} \\
\hline $\begin{array}{l}13-1,102 \\
13-1,120 \\
13-2,15 \\
13-2,28 \\
13-2,45 \\
13-2,82 \\
13-2,148 \\
13-3,144\end{array}$ & $\begin{array}{r}293 \\
151 \\
289 \\
124 \\
336 \\
88 \\
91 \\
34\end{array}$ & $\begin{array}{r}8 \\
8 \\
13 \\
30 \\
1 \\
26 \\
27 \\
9\end{array}$ & $\begin{array}{r}291 \\
150 \\
288 \\
123 \\
341 \\
90 \\
99 \\
37\end{array}$ & $\begin{array}{l}6 \\
7 \\
10 \\
13 \\
-7^{\mathrm{a}} \\
25 \\
24 \\
11\end{array}$ & $\begin{array}{r}50 \\
100 \\
150 \\
200 \\
100 \\
100 \\
100 \\
200\end{array}$ & $\begin{array}{l}155 \\
170 \\
173 \\
165 \\
183 \\
189 \\
177 \\
192\end{array}$ & $\begin{array}{l}77 \\
86 \\
86 \\
93 \\
85 \\
92 \\
77 \\
82\end{array}$ \\
\hline \multicolumn{8}{|l|}{ Site 313} \\
\hline $\begin{array}{l}43-2,41 \\
43-2,93 \\
44-1,71 \\
44-1,115 \\
44-2,64 \\
44-2,127 \\
44-3,6 \\
44-3,146\end{array}$ & $\begin{array}{r}134 \\
303 \\
85 \\
275 \\
63 \\
46 \\
231 \\
25\end{array}$ & $\begin{array}{r}-23 \\
-31 \\
-5 \\
2 \\
-13 \\
2 \\
2 \\
-26 \\
47\end{array}$ & $\begin{array}{r}132 \\
305 \\
74 \\
277 \\
74 \\
52 \\
230 \\
80\end{array}$ & $\begin{array}{l}-41 \\
-34 \\
-40 \\
-42 \\
-36 \\
-20 \\
-27 \\
-51\end{array}$ & $\begin{array}{l}300 \\
200 \\
200 \\
300 \\
300 \\
150 \\
300 \\
300\end{array}$ & $\begin{array}{r}101 \\
148 \\
101 \\
95 \\
161 \\
123 \\
108 \\
34\end{array}$ & $\begin{array}{r}51 \\
77 \\
51 \\
48 \\
79 \\
62 \\
54 \\
9\end{array}$ \\
\hline
\end{tabular}

Note: The declination (D) and inclination (I) are shown for NRM and at the optimum demagnetizing field $\left(H_{d}\right)$. Although the actual declinations are arbitrary, the relative change for each sample illustrates the magnetization stability. The median destructive field (MDF) and the ratio of the remanent intensity after 100-oe AF demagnetization $\left(J_{100}\right)$ to the NRM also indicate individual sample stabilities.

${ }^{\mathrm{a}}$ These samples were probably inverted.

\section{Directions of Remanent Magnetizations}

The declinations of DSDP samples are useful only for internal comparisons of magnetization stability, as in Table 2. On the other hand, the inclinations are meaningful because the vertical direction is known for each sample. Mixed inclinations occasionally are found, as at Hole $303 \mathrm{~A}$ (Table 2). It is possible that these represent different cooling units that formed in periods of opposite geomagnetic field polarities. It is also possible, especially with small DSDP basalt core fragments, that mislabeling of the upward vertical direction could have occurred. For averaging purposes, all samples from the same site were given the polarity of the majority, and the mean stable inclination at each site was calculated.

The NRM inclination expected at each site depends on the polarity of the geomagnetic field at the time of formation of the site, and the site paleolatitude at that time. Analysis of magnetic anomaly profiles and comparison with other Pacific plate paleomagnetic studies were used to predict the paleolatitude of each site (Table 3 ). The site mean remanent inclinations were used to determine the paleolatitude record in the basalts. At Hole $303 \mathrm{~A}$ and Site 304 these agree extremely well, at Site 307 the agreement is poorer, and no comparison was made at Site 313 . 
TABLE 3

Comparison of Observed Site Mean Stable Remanent Inclinations

and the Paleolatitudes Inferred From Them With Paleolatitudes Predicted From Oceanic Magnetic Anomaly Analysis

\begin{tabular}{lccccc}
\hline Site & $\begin{array}{c}\text { Magnetic } \\
\text { Anomaly }\end{array}$ & Polarity & $\begin{array}{c}\text { Mean } \\
\text { Inclination }\end{array}$ & Paleolatitude & $\begin{array}{c}\text { Predicted } \\
\text { Paleolatitude }\end{array}$ \\
\hline $303 \mathrm{~A}$ & $\mathrm{M}-4$ & $\mathrm{~N}$ & $-11^{\circ} \pm 1^{\circ}$ & $5.8^{\circ} \mathrm{S}$ & $55^{\circ} \mathrm{S}$ \\
304 & $\mathrm{M}-9$ & $\mathrm{R}$ & $22^{\circ} \pm 2^{\circ}$ & $11.0^{\circ} \mathrm{S}$ & $10^{\circ} \mathrm{S}$ \\
307 & $\mathrm{M}-21$ & $\mathrm{~N}$ & $11^{\circ} \pm 4^{\circ}$ & $5.6^{\circ} \mathrm{N}$ & $15-20^{\circ} \mathrm{S}$ \\
313 & - & - & $-36^{\circ} \pm 3^{\circ}$ & $20^{\circ}(\mathrm{N}$ or S $)$ & - \\
\hline
\end{tabular}

It has been found that the inclinations measured in DSDP basalts frequently (but not always) show large discrepancies with inclinations predicted from plate reconstructions. This is thought to be primarily due to the nonaveraging of secular variation in the quickly chilled DSDP basalts, although other factors also contribute (inaccuracy of plate reconstructions, for example). The inclination discrepancies at 26 DSDP sites ranged from $0^{\circ}$ to $40^{\circ}$, and averaged $14^{\circ}$ (Lowrie, in press). Clearly, the paleolatitude discrepancy at Site $307\left(20^{\circ}-25^{\circ}\right)$ corresponds to an inclination discrepancy as large as any found at other DSDP sites. The reasons for this will be discussed further below.

\section{MAGNETIC ANOMALY PROFILES AND PACIFIC PLATE MOTION}

The results of the analyses of the basalt samples that are described above demonstrate that the basalts have reasonably stable remanences that accurately recorded the ambient field directions present when the lava originally was extruded and cooled. Accepting this, we shall now explore the implications of these remanent inclination measurements for the plate tectonic history of the Pacific plate. In the following discussion we shall ignore Site 313 which was drilled on a seamount in the northern Mid-Pacific Mountains. This is a considerably younger site than the other three, and it is impossible to estimate independently its polarity and thus compute its paleolatitude. The tectonic history of the Mid-Pacific Mountains iiisalso a speculative subject, while the other three sites can be compared to the evolution of the magnetic lineation patterns of the western Pacific.

Basalts from Sites 303A, 304, and 307 all have much shallower remanent inclinations than the ambient or dipole inclination values at any of these sites. We can infer immediately that they were formed considerably ccccdloser to the magnetic equator than their present positions and have thus undergone a net northward motion since the late Mesozoic. This is in accord with similar suggestions by previous investigators (Uyeda and Richards, 1966; Vacquier and Uyeda, 1967; Vine, 1968; Francheteau et al., 1970; Larson and Chase, 1972). All of these sites have remanent inclinations corresponding to paleolatitudes of $15^{\circ}$ or less, so they were formed somewhere within a band $30^{\circ}$ wide that is symmetric about the equator. Tectonic reconstructions are not sufficiently precise to predict whether the latitude of formation was northern or southern for any of these sites. Rather, we would like to determine this independently and use it to constrain future tectonic reconstructions.
With DSDP samples the vertical direction is known, but the azimuthal orientation is not determined. Thus, the problem of choosing a northern or southern latitude of formation is really a problem of independently determining if the site is normally or reversely magnetized. This can be estimated from magnetic model studies for basalts that were recovered from identifiable magnetic lineations. Hole 303A and Site 304 were drilled in the middle of a well-defined portion of the Japanese lineation pattern, while Site 307 was drilled on the northwestern corner of the Hawaiian lineations (Larson and Chase, 1972) where a detailed presite survey provides additional information (see Chapter 6, Site 307). Sites $303 \mathrm{~A}$ and 304 are shown located in Figure 3 with respect to the $\mathrm{C} 1405$ magnetic profile that runs directly between the sites and passes within $5 \mathrm{~km}$ of the site locations in each case. The identifications of lineations M4 to M9 on the C1405 are from Larson and Chase (1972); however, the exact block model boundaries are not the
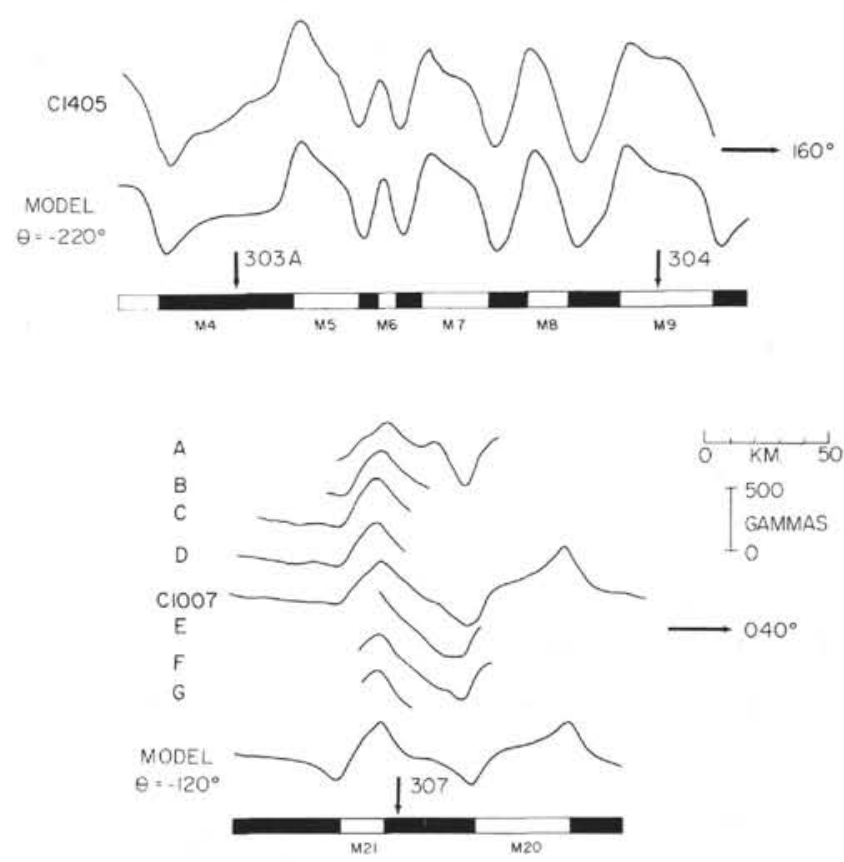

Figure 3. Projected magnetic anomaly profiles in the vicinities of Sites 303A, 304, and 307 compared with model anomaly profiles computed from the illustrated block models. Block boundaries determined by phase-shifting C1405 and C1007 profiles to symmetry (Figure 4). M-lineation correlations from Larson and Chase (1972). 
ones used to make this correlation. The block model boundaries used by Larson and Chase (1972) are a linear contraction of a block model built to match the Phoenix lineations. While this contracted block model can be used to generate a model anomaly profile that is a sufficient resemblance to the $\mathrm{C} 1405$ and adjacent profiles to make a valid correlation, it is not a very accurate estimate of the block boundary locations on the Japanese lineations. To more accurately estimate these locations, we manipulated the $\mathrm{C} 1405$ profile in a manner described by Schouten and McCamy (1972). This involves Fourier transforming the magnetic profile into the frequency domain and then phase shifting the data, so that it appears as a more nearly symmetric "square wave" when retransformed and plotted in the space domain (Figure 4). This is a doubly useful technique in this particular analysis. First, the transitions from positive to negative anomalies that define the underlying block boundaries are more precisely located in the phase-shifted profile. Second, the amount of phase shift necessary to achieve symmetry determines a great semicircle that is a locus of points which are acceptable paleomagnetic pole locations for the oceanic crust associated with this set of
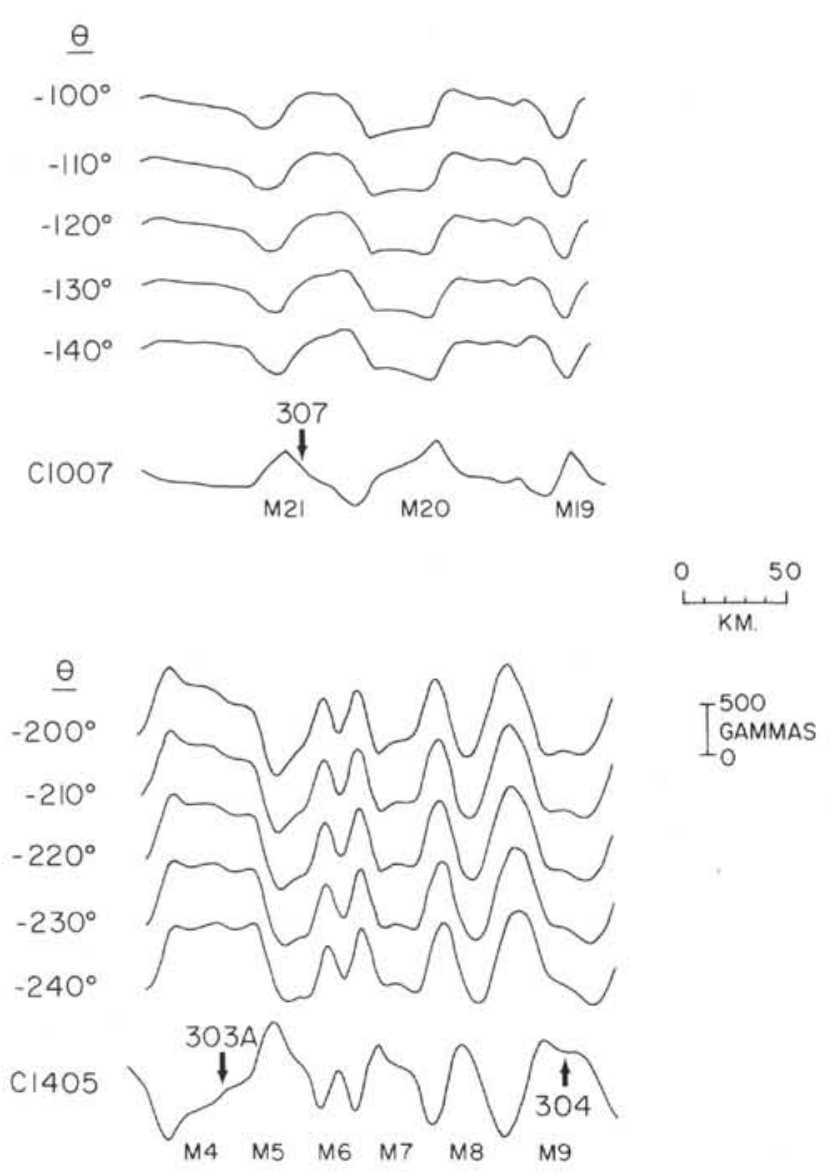

Figure 4. Profiles labeled $C 1405$ and $C 1007$ are the original magnetic anomaly data. Other profiles are these data phase-shifted by various phase angles $(\theta)$ using the technique of Schouten and McCamy (1972). C1007 appears symmetric at $\theta=-110^{\circ}$ to $-130^{\circ}$ while C1405 has $a$ broader symmetry range of $\theta=-200^{\circ}$ to $-240^{\circ}$. magnetic anomaly measurements (Cande and Schouten, 1972). Larson and Chase (1972) made use of a technique similar to the latter method that allowed them to define an area that should enclose the paleomagnetic pole location for the Pacific plate for magnetic anomaly M1 to M10 time (Early Cretaceous). This area is shown as the irregular polygon centered at about $50^{\circ} \mathrm{N}, 30^{\circ} \mathrm{W}$ on Figure 5.

We conclude from the analysis described above that the $\mathrm{C} 1405$ profile, shown in its original form in Figure 3, has a relatively wide variation of symmetry, corresponding to a range in the symmetry parameter, $\theta$ (Schouten and $\mathrm{McCamy}, 1972$ ) of $-200^{\circ}$ to $-240^{\circ}$ (Figure 4). C1405 is shown in Figure 3 compared with a block model that results from the same analysis that was used to compute a model profile with $\theta=-220^{\circ}$. Even though there is a broad range of symmetry in the $\mathrm{C} 1405$ profile (Figure 4), it is obvious that Hole 303A and Site 304 both lie at large distances from inferred block boundaries $(23 \mathrm{~km}$ and $16 \mathrm{~km}$, respectively, to the nearest

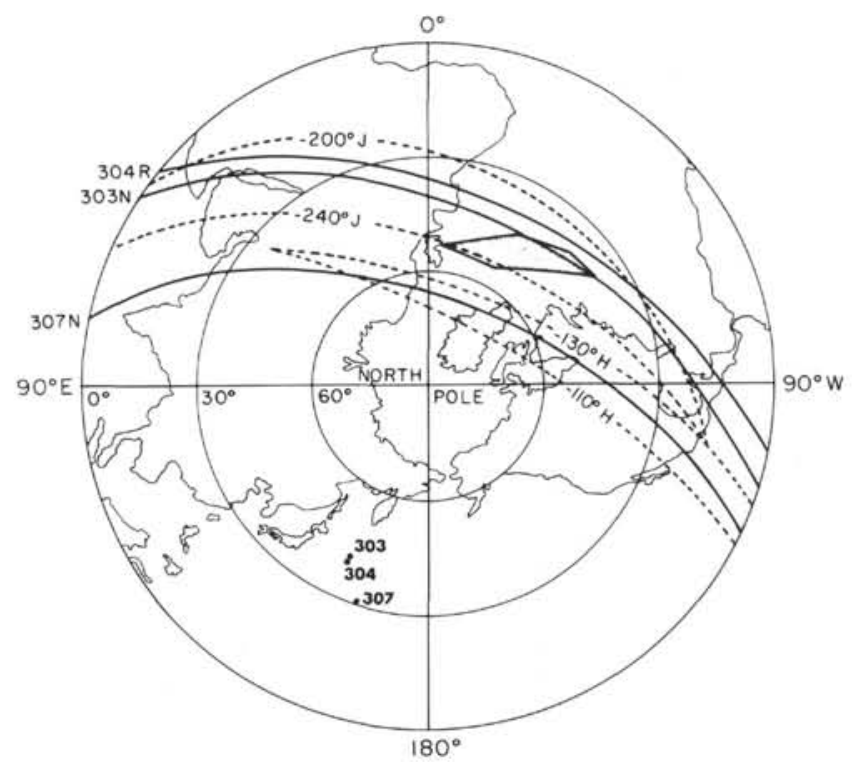

Figure 5. Azimuthal equidistant polar projection of the northern hemisphere with paleomagnetic pole location data from rock magnetization and magnetic anomaly studies. Dots labeled 303, 304, and 307 are the site locations. The irregular polygon (stippled) encloses the paleomagnetic pole location for the Pacific plate from M1 to M10 time (Larson and Chase, 1972). 303N, 304R, and $307 N$ are the Northern Hemisphere portions of small circles along which paleomagnetic poles for the Pacific plate may lie assuming that the sites are normally $(N)$ or reversely $(R)$ magnetized, and that the remanent inclination directions were generated by an axial dipole. $-200^{\circ} \mathrm{J}$, $-240^{\circ} \mathrm{J},-110^{\circ} \mathrm{H}$, and $-130^{\circ} \mathrm{H}$ are the Northern Hemisphere positions of great semicircles corresponding to paleomagnetic pole locations derived from the crosssectional shapes of the $\mathrm{C} 1405$ and $\mathrm{C1007}$ profiles. $-200^{\circ} \mathrm{J}$ to $-240^{\circ} \mathrm{J}$ bound a "lune of confidence" for the Japanese $(J)$ lineations while a "lune of confidence" for the Hawaiian (H) lineations is bounded by $-110^{\circ} \mathrm{H}$ and $-130^{\circ} \mathrm{H}$. 
block boundary). Also, the $\mathrm{C} 1405$ and adjacent profiles, along with the original model study of Larson and Chase (1972), suggest that there were no very short magnetic polarity events during the time represented by the $\mathrm{C} 1405$ profile that are not shown on Figure 3. If this is the case, we conclude that Hole $303 \mathrm{~A}$ was drilled on normally magnetized crust and that Site 304 was drilled on reversely magnetized crust. These conclusions could be invalidated not only by undetected polarity events of short duration, but also by abnormally wide intrusion centers that inject oppositely polarized material into adjacent crustal blocks, or are the source for extrusive flows that spread out over large lateral distances. We think that the latter two possibilities are quite unlikely because the definition of these magnetic anomalies suggests that they were formed at a very narrow spreading center. Studies to quantify such widths have indicated that well-defined anomalies are generated at spreading centers with widths on the order of a few $(<5) \mathrm{km}$ (Atwater and Mudie, 1973; Harrison, 1968).

The $-12^{\circ}$ inclination value and the normal polarity determination for Hole $303 \mathrm{~A}$, and the $+21^{\circ}$ inclination value and reversed polarity determination for Site 304 result in paleolatitude estimates of $6^{\circ} \mathrm{S}$ and $11^{\circ} \mathrm{S}$, respectively. These correspond to possible paleomagnetic pole locations that form small circles of radii $84^{\circ}$ and $79^{\circ}$ whose centers are the antipode locations of Hole 303A and Site 304. The portions of these circles (303N, 304R) that occur in the Northern Hemisphere are shown in Figure 5 compared with the paleomagnetic pole location for M1 to M10 determined by Larson and Chase (1972) and the lune of confidence defined by the $\theta=-200^{\circ}$ to $-240^{\circ}$ phase shift for the $\mathrm{C} 1405$ profile. The agreement between these independent measurements (rock magnetism and magnetic anomalies) is remarkably good, considering the scatter that is often observed when comparing paleomagnetic results with tectonic reconstructions (Lowrie, in press). While a good agreement occurs in these two cases, it could still be partially fortuitous because any individual flow sampled by drilling will record the magnetic field direction present at an instant (hours to days) of time while the magnetic anomalies record an effect integrated over hundreds to thousands of years. The former measurement presumably could contain wide variations of direction of the dipole or multipole paleofield that should average out to an axial dipole if sampled in enough rocks or measured by magnetic anomaly lineations.

We now turn to Site 307 drilled on anomaly M21, more than 20 m.y. older than either Hole 303A or Site 304 and located on the Hawaiian lineation pattern. Site 307 is located within $14 \mathrm{~km}$ of the $\mathrm{Cl} 1007$ profile and is further defined by a detailed survey whose magnetic results also are shown in Figure 3 in projected form labeled A through G. Profile $\mathrm{C} 1007$ was analyzed (Figure 4) as was C1405, but profiles A to G could not be phase shifted because the technique generates edge effects at the ends of the profiles that in these cases occupy most of the short data sequences. The phase shift necessary for symmetry to occur in the $\mathrm{C} 1007$ profile is $\theta$ $=-110^{\circ}$ to $-130^{\circ}$ (Figure 4) which seems to be a more uniform value than the range determined on the C1405 profile, although fewer anomalies are involved in the analysis (M19 to M21). The block boundaries determined from this analysis are shown in Figure 3, along with a model profile computed from this structure for $\theta$ $=-120^{\circ}$. This analysis indicates that Site 307 is located on normally magnetized crust, but we are not as certain of this result as we are of the polarity determinations for Hole 303A and Site 304. First, as shown in Figure 3, Site 307 occurs within $6 \mathrm{~km}$ of a block boundary, considerably closer than the locations of Sites $303 \mathrm{~A}$ and 304 to block boundaries. Second, there is probably a small reversed event in the normal interval between M20 and M21 that is only clearly apparent in anomaly profile A in Figure 3. Site 307 occurs between profiles E and F, where the location of this event is not obvious. These uncertainties should be considered in the following discussion.

The small circle $(307 \mathrm{~N})$ corresponding to a paleolatitude of formation of $7^{\circ} \mathrm{N}$ is shown plotted on Figure 5 for Site 307. Also shown are the great semicircles for $\theta=$ $-110^{\circ}$ to $-130^{\circ}$ that form a lune of confidence for the $\mathrm{C} 1007$ profile that is bisected by the $307 \mathrm{~N}$ curve. The fact that these two measurements are coincident suggests that both the rocks and magnetic anomalies at Site 307 recorded the paleomagnetic field in the same way. If we assumed that Site 307 is reversely magnetized, the small circle corresponding to a paleolatitude of formation would plot about $10^{\circ}-15^{\circ}$ further from the north pole, approximately coincident with the $240^{\circ} \mathrm{J}$ line on Figure 5. The location of the paleomagnetic North Pole information shown in Figure 5 is extraordinary. First, it is well beyond the intersection discussed earlier that Larson and Chase (1972) determined for M1 to M10 from the Japanese, Hawaiian, and Phoenix lineations. The phase shift for $\mathrm{C} 1007$ at Site 307 corresponds to $\theta=-110^{\circ}$ to $-130^{\circ}$, while $\theta=-140^{\circ}$ to $160^{\circ}$ for the Hawaiian lineation portion of the M1 to M10 intersection.

The location of the Site 307 paleopole information is especially curious because it connotes a northern paleolatitude of formation as opposed to Hole 303A and Site 304 which were formed south of the equator. Today Site 307 lies more than $1200 \mathrm{~km}$ south of Hole 303A and Site 304 and would be presumed to have formed even farther south relative to Hole $303 \mathrm{~A}$ and Site 304 if the Pacific plate has moved uniformly northwards in the past 150 m.y. (Table 3). Even if Site 307 is assumed to be reversely magnetized, it would have formed at the same paleolatitude as Hole 303A and north of Site 304. Site 307 is about 25 m.y. older than Hole 303A and Site 304, and this coupled with the above information suggests that a uniform northward motion of the plate was not the case during the Early Cretaceous. An alternative hypothesis is that the motion of the Pacific plate at that time had a large rotational component that could have allowed Site 307 to form north of the equator and Hole 303A and Site 304 to be formed 25 m.y. later in the Southern Hemisphere. While such a large rotational component seems unlikely for the huge Pacific plate of today, it should be remembered that the Pacific plate of the Early Cretaceous was a much smaller entity bounded by the Japanese, Hawaiian, and Phoenix lineations and that 
small plates often tend to have large rotational components.

We consider a dominantly rotating Pacific plate from 150 to $110 \mathrm{~m} . \mathrm{y}$. to be a speculative hypothesis at this time. However, the data presented above strongly support a net northward motion of the Pacific plate since the late Mesozoic. This motion has been determined from rock magnetism and magnetic anomalies, and these independent methods yield concordant results at all three DSDP sites.

\section{REFERENCES}

Ade-Hall, J.M., Palmer, H.C., and Hubbard, T.P., 1971. The magnetic and opaque petrologic response of basalts to regional hydrothermal alteration: Geophys. J. Roy. Astro. Soc., v. 24, p. 137-174.

Atwater, T. and Mudie, J.D., 1973. Detailed near-bottom geophysical study of the Gorda Rise: J. Geophys. Res., v. 78, p. 8665-8686.

Briden, J.C., 1972. A stability index of remanent magnetism: J. Geophys. Res., v. 77, p. 1401-1405.

Cande, S.C. and Schouten, A., 1971. Paleomagnetic poles from sea-floor spreading anomalies (abstract): EOS, v. 53, p. 352 .

Francheteau, J., Harrison, C.G.A., Sclater, J.G., and Richards, M.L., 1970. Magnetization of Pacific sea- mounts: a preliminary polar curve for the northeastern Pacific: J. Geophys. Res., v. 75, p. 2035-2061.

Harrison, C.G.A., 1968. Formation of magnetic anomaly patterns by dyke injection: J. Geophys. Res., v. 73, p. 2137 2142.

Larson, R.L. and Chase, C.G., 1972. Late Mesozoic evolution of the western Pacific Ocean: Geol. Soc. Am. Bull., v. 83, p. 3627-3644.

Larson, R.L. and Pitman, W.C., III, 1972. Worldwide correlation of Mesozoic magnetic anomalies, and its implications: Geol. Soc. Am. Bull., v. 83, p. 3645-3662.

Lowrie, W., in press. Oceanic basalt magnetic properties and the Vine and Matthews hypothesis: Zeit. fur Geophys.

Marshall, M. and Cox, A., 1972. Magnetic changes in pillow basalt due to sea floor weathering: J. Geophys. Res., v. 77, p. 6459-6469.

Schouten, H. and McCamy, K., 1972. Filtering marine magnetic anomalies: J. Geophys. Res., v. 77, p. 7089-7099.

Uyeda, S. and Richards, M.L., 1966. Magnetization of four Pacific seamounts near the Japanese Islands: Tokyo Univ. Earthquake Res. Inst. Bull., v. 44, p. 179-213.

Vacquier, V. and Uyeda, S., 1967. Paleomagnetism of nine seamounts in the western Pacific and of three volcanos in Japan: Tokyo Univ. Earthquake Res. Inst. Bull., v. 45, p. 815-848.

Vine, F.J., 1968. Paleomagnetic evidence for the northward movement of the north Pacific basin during the past 100 m.y. (abstract): Am. Geophys. Union Trans., v. 49, p. 156. 